\title{
Sterilization costs and exchange rate targeting
}

\author{
Kenneth Kletzer Mark M. Spiegel ${ }^{*}$
}

April 3, 2000

\begin{abstract}
This paper examines the movements of exchange rates and capital inflows in an environment where an optimizing central bank pursuing the joint goals of inflation and output targeting engages in costly sterilization activities. Our results predict that when faced with increased sterilization costs, the central bank will choose to limit its sterilization activities allowing target variables, such as the nominal exchange rate, to adjust.

We then test the predictions of a linearized version of the saddle-path solution to the model for a cross-country panel of developing countries. We use IV, GMM and simultaneous equation specifications to allow for the endogeneity of capital inflows. Our results confirm that monetary policy does respond to sterilization costs.
\end{abstract}

\section{J.E.L. Classification Number: F32}

Keywords: Sterilization, capital inflows, exchange rates

${ }^{*}$ Warren Chiang and Laura Haworth provided excellent research assistance. We thank Carlos Vegh, participants in the UCLA international economics workshop and the FRBSF-U.C. Berkeley summer camp for helpful comments. Remaining errors are our own. 


\section{Introduction}

With the turbulent capital movements experienced by developing nations in recent years, many nations have engaged in efforts to slow large movements of capital into a nation. There are a number of reasons why nations resist capital inflow surges. First, there are a number of concerns about the implications of capital inflows for macro variables. Under fixed exchange rate regimes, capital inflows can be inflationary, as prices of domestic non-tradables are bid up in the wake of a capital inflow surge. There are also concerns about movements in real exchange rates, growth in the money stock, and a deterioration of the current account (Calvo, Leiderman and Reinhart (1996)).

Second, there are concerns about the impact of these flows on domestic financial markets. There is a suspicion that large capital inflows may leave a nation exposed to rapid capital outflows: some capital inflows may be in the form of "hot money," whose owners are likely to flee at the first sign of difficulty. Another source of instability is that a nation may have difficulty allocating very rapid capital inflows into their most productive uses. This may lead to poor investment decisions and bankruptcy in the wake of the inflow surge. This problem is

particularly severe for developing countries, whose financial sectors are relatively unsophisticated.

Finally, governments may wish to limit the magnitude of a capital inflow surge because of moral hazard difficulties. Investors may be willing to invest in even poor projects in a developing country if they perceive some sort of government guarantee of their return on their project. Indeed, the onset of the perception that these government guarantees were not credible has been raised as one source 
of the Asian currency crisis (Burnside, et al, [1998]).

The choices available to policy makers wishing to stem capital inflows are limited. Policy makers confronted with a surge in capital inflows can either implement some form of capital control, through either a quantitative restriction on inward capital movements or a tax on these movements, or attempt to mitigate the inflationary impact of these capital flows by sterilized exchange rate intervention. Sterilization is usually the first policy response to a sudden rise in financial capital inflows. Under this policy, central banks swap domestic securities, such as government treasury obligations, for incoming foreign assets. The net impact of a sterilization exercise is that the monetary base is unchanged, but the share of foreign reserves in central bank asset holdings have increased. ${ }^{1}$

A number of studies (e.g. Calvo, Leiderman and Reinhart [1993] and Frankel and Okongwu [1996]) question both the feasibility and desirability of sterilization efforts. Drawing on warnings initially raised by Calvo [1991], these studies argue that there are "quasi-fiscal" costs associated with sterilization as central banks exchange high-yielding domestic government debt for foreign securities typically paying lower nominal yields.

Estimates of quasi-fiscal costs based on observed spreads between domestic and foreign assets and the size of foreign reserve increases for developing country central banks engaging in sterilization activities indicate that these costs can become large. Calvo, et al [1993] and Khan and Reinhart [1994] report estimates

\footnotetext{
${ }^{1}$ More draconian forms of limiting capital inflows include raising bank reserve requirements or taxing international capital movements. See Spiegel [1995] and Reinhart and Smith [1998] respectively for discussions of adverse macroeconomic implications of these alternative instruments.
} 
for Latin America between 0.25 and 0.5 percent of GDP. Kletzer and Spiegel [1998] report estimates of quasi-fiscal costs for the Pacific Basin nations with similar average magnitudes, but their results suggest that capital inflow surges can result in quarterly peaks above one percent of GDP for nations such as Singapore and Taiwan. However, Kletzer and Spiegel caution that these are "upper-bound" estimates of the magnitude of quasi-fiscal costs, since domestic bond spreads can incorporate true default risk premia.

As a result, there are many sources of exchange rate premia under which uncovered interest rate parity is maintained. For example, Craine [1999] has demonstrated that an exchange rate premium will exist when governments lack complete credibility in maintaining a nominal exchange rate peg, even in cases where the exchange rate regime is fundamentally sound in the sense of the central bank possessing adequate reserves to defend the announced peg. The reason is that there is a true possibility of ending up in an equilibrium in which the peg is not defended, even if its defense is feasible. A bond spread stemming from sovereign risk of this type does not represent a true deviation from interest rate parity.

Alternatively, one could turn to asymmetric information as a source of a true deviation from interest rate parity. Consider a government that knows that it is a good credit risk, but is pooled with a number of nations that are poor credit risks because of information costs. Such an outcome would represent a true deviation from interest rate parity, and the government would correctly consider a swap of domestic for foreign debt as costly.

This paper considers the decision problem for a rational central bank faced with a deviation from interest rate parity corrected for default risk, so that steril- 
ization is costly. The central bank chooses the exchange rate as its instrument of optimal policy. Other models which consider optimal sterilization policy include Roubini [1988] which considers optimal sterilization policies in a static setting, and Natividad and Stone [1990], which consider optimal policies under imperfect capital mobility. Our model differs from the latter by explicitly incorporating the implications of sterilization policy for the consolidated government budget constraint into the central bank's decision problem. ${ }^{2}$

The paper therefore follows the literature which models speculative attacks on exchange rate regimes based on endogenous rational central bank policies, e.g. Obstfeld [1986] and [1995] and Buiter [1987]). This is distinct from the classical speculative attack literature, exemplified by Krugman [1979] and Flood and Garber [1984a, 1984b], in which the process of domestic credit creation is taken as exogenous.

We use a model of exchange rate determination for a small open economy in which domestic monetary policy is set by an optimizing central bank in an environment in which sterilization is costly. To obtain short-term non-neutrality, we introduce wage stickiness. The central bank then chooses the nominal exchange rate so as to minimize movements in the nominal rate and deviations from its output target. As in Buiter [1987], this optimal policy is chosen subject to an inter-temporal budget constraint. Our results demonstrate that the costs of sterilization, which impact on the inter-temporal budget constraint, are incorporated by the central bank in its monetary policy decisions.

We then test the predictions of the saddle-path stable solution of the model

\footnotetext{
${ }^{2}$ Also, see Daniels [1997] for a consideration of strategic determinants of sterilization activity in a two-country framework.
} 
for a panel of 24 "dirty-floating" nations during the high capital-inflow period from 1984 through 1992. We use IV, GMM and simultaneous equation specifications to allow for the endogeneity of capital inflows. Our results strongly confirm the primary implication of the theory that monetary policy does respond to sterilization costs. In particular, increased sterilization costs are shown to be positively associated with increases in the rate of change in the nominal exchange rate. However, other aspects of the model yield mixed results. The significance of predictions of the theoretical model for coefficient values are found to be sensitive to our treatment for endogeneity, and cross-coefficient restrictions implied by the strong functional form of the theory are rejected by the data.

\section{Capital inflows and optimal central bank intervention}

\subsection{Exchange rate determination under nominal wage rigidity}

We begin with a standard monetary model of the exchange rate with nominal wage rigidities. All variables, except domestic and foreign interest rates, are expressed in logarithms. We assume that the log of aggregate supply, $y_{t}$, is an increasing function of the inverse of real wages and is subject to an identical independent zero mean shock, $u_{t}$, each period:

$$
y_{t}=\alpha\left(p_{t}-w_{t}\right)+u_{t}
$$

where $w_{t}$ is the average wage rate, $p_{t}$ is the price level, and $\alpha$ is an exogenous constant.

We assume that all agents in the economy are rational and sign one-period nominal wage contracts for the following period. We normalize equilibrium full- 
employment output to unity, so that

$$
w_{t}=E_{t-1} p_{t} \quad \text { and } \quad E_{t-1} y_{t}=0 .
$$

Equilibrium in the money market is assumed to be given by

$$
m_{t}-p_{t}=\varphi y_{t}-\delta i_{t+1}+\nu_{t}
$$

where $m_{t}$ is the supply of domestic currency, $i_{t+1}$ is the interest rate prevailing on claims held at the end of period $t$ and $\nu_{t}$ is a possibly serially-correlated disturbance to money demand. We also impose purchasing power parity,

$$
s_{t}+p_{t}^{*}=p_{t}
$$

where $s_{t}$ is the spot exchange rate (in logs) expressed as units of domestic currency per unit of foreign currency.

As we noted in the introduction, we assume that uncovered interest rate parity fails to hold. Define $\gamma_{t}$ as the deviation from uncovered interest rate parity on public debt denominated in domestic currency. Assuming that the true probability of default on government debt is zero, $\gamma_{t}$ satisfies

$$
i_{t+1}=i_{t+1}^{*}+\left(E_{t} s_{t+1}-s_{t}\right)+\gamma_{t}
$$

The foreign price level is held constant and normalized to one for simplicity $\left(p_{t}^{*}=\right.$ $0)$. Combining these relationships leads to the exchange rate equation,

$$
s_{t}=\Omega^{-1}\left[\left(m_{t}+\delta\left(i_{t+1}^{*}+\gamma_{t}\right)-\nu_{t}\right)+\alpha \varphi E_{t-1} s_{t}-\varphi u_{t}+\delta E_{t} s_{t+1}\right] .
$$

where $\Omega$ is the constant term

$$
\Omega=1+\delta+\alpha \varphi
$$


This can be solved forward ruling out speculative bubbles by imposing the condition,

$$
\lim _{v \rightarrow \infty}\left(\frac{\delta}{1+\delta}\right)^{v-t} E_{t} s_{v+1}=0
$$

to obtain the exchange rate equation,

$$
s_{t}=\Omega^{-1}\left\{m_{t}+E_{t}\left[\sum_{j=t+1}^{\infty}\left(\frac{\delta}{1+\delta}\right)^{j-t}\left(m_{j}+\delta\left(i_{j}^{*}+\gamma_{j}\right)-v_{j}\right)\right]+\varphi\left(\alpha w_{t}-u_{t}\right)\right\} .
$$

\subsection{Central bank decision problem}

The central bank's decision problem is to choose the spot rate to minimize an inter-temporal quadratic loss function defined over movements in the nominal exchange rate and deviations from $y^{*}$, a target level for output,

$$
L_{t}=\frac{1}{2} E_{t} \sum_{s=t}^{\infty} \beta^{s-t}\left(\theta\left(s_{t}-s_{t-1}\right)^{2}+\left(y_{t}-y^{*}\right)^{2}\right) .
$$

subject to the inter-temporal budget constraint for the consolidated government. ${ }^{3}$ The single-period budget identity is given in levels (not logarithms) by

$$
B_{t}=\left(1+i_{t}\right) B_{t-1}+G_{t}+\left[S_{t} R_{t}-\left(1+i_{t}^{*}\right) S_{t} R_{t-1}-\left(M_{t}-M_{t-1}\right)\right]
$$

where $B_{t}, R_{t}$ and $M_{t}$ are stocks of privately-held public debt, central bank reserves and base money at the end of period $t$. $G_{t}$ is consolidated primary deficit of the public sector for period $t$, and $S_{t}$ is the spot exchange rate in period $t$. The term

\footnotetext{
${ }^{3}$ We model the central bank decision problem as the choice of the nominal spot rate for simplicity. Operationally, the central bank may be seen as conducting monetary policy which is consistent with its chosen spot exchange rate.
} 
in square brackets is the transfer from the central bank to the fiscal authority in units of domestic currency.

A capital inflow during period $t$ leads to an increase in foreign reserves given by $\Delta R_{t} \equiv\left(R_{t}-R_{t-1}\right)$. The appropriate discount factor to apply to future public sector budget surpluses equals

$$
I_{t, t+j}=\prod_{i=t+1}^{t+j} \frac{1}{\left(1+i_{i}\right)}
$$

We also impose the conventional solvency condition on the public sector,

$$
\lim _{T \rightarrow \infty} E_{t}\left[\Pi_{j=t}^{T}\left(1+i_{j}\right)^{-1}\right] B_{T}=0
$$

Sterilization of a capital inflow at date $t$ leads to a present value increase in future surpluses inclusive of monetization necessary to maintain public sector solvency if $\gamma_{t}$ excludes, as we assume here, any correctly-priced default risk premium. The present value cost of sterilizing a capital inflow of size $\Delta R_{t}$ is

$$
E_{t} \sum_{j=1}^{\infty} I_{t, t+j}\left[\gamma_{t+j} S_{t} \Delta R_{t}\right]
$$

Unless the government cuts expenditures or increases taxes, the net cost of sterilization must eventually be monetized.

If the date $t$ capital inflow is fully monetized at time $t+T$, then public sector solvency is maintained if the date $t+T$ increase in the domestic money supply equals

$$
M_{t+T}-M_{t+T-1}=S_{t} \Delta R_{t}+E_{t} \sum_{j=1}^{T}\left[\gamma_{t+j} S_{t} \Delta R_{t}\right] \prod_{i=t+1}^{t+j}\left(1+i_{i}\right),
$$

the initial capital inflow in domestic currency plus the accumulated costs of sterilized intervention. The date $t$ present value of future monetization at date $t+T$ 
is

$$
\left(M_{t+T}-M_{t+T-1}\right) I_{t, t+T}=S_{t} \Delta R_{t}+E_{t} \sum_{j=1}^{T} I_{t, t+j}\left[\gamma_{t+j} S_{t} \Delta R_{t}\right],
$$

which grows with the horizon $T$ for positive $\gamma_{t+j}$. The costs of sterilization at date $t$ can also be continuously monetized through monetary expansions equal to $\gamma_{s} S_{t} \Delta R_{t}$ at every date $s>t$. Without sterilization costs $\left(\gamma_{t}=0\right)$, the expected future money supply increase needed to maintain public sector solvency after a sterilized capital inflow is zero.

If a capital inflow of size $\Delta R_{t}$ is not sterilized, the currency depreciates at date $t$ by the amount

$$
\Delta s_{t}=\Omega^{-1} \frac{S_{t} \Delta R_{t}}{M_{t-1}}
$$

using equation 2.7. Sterilization at date $t$ followed by the eventual monetization of the resulting increase in public debt at time $t+T$ leads to a depreciation of the home currency at time $t+T$ given by

$$
\Delta s_{t+T}=\Omega^{-1}\left(\left[\frac{S_{t} \Delta R_{t}}{M_{t+T-1}}\right]+\sum_{j=1}^{T}\left[\frac{\gamma_{t+j} S_{t} \Delta R_{t}}{M_{t+T-1}}\right] \prod_{i=t+1}^{t+j}\left(1+i_{i}\right)\right) .
$$

The currency also depreciates at date $t$ given future monetization by the amount

$$
\Delta s_{t}=E_{t}\left(\frac{\delta}{1+\delta}\right)^{T} \Delta s_{t+T}
$$

Sterilization therefore has the same effect as borrowing reserves. It postpones an eventual depreciation or fiscal contraction. With an public debt interest premium, sterilization leads to a larger future depreciation and a current depreciation. Buiter [1987] shows how borrowing reserves can either postpone or advance the date of an eventual speculative attack under a pegged exchange rate. In his model, there are no costs to sterilization; foreign currency denominated public debt will 
pay the same rate of interest as foreign public debt. Applying our model to a collapsing exchange-rate peg favors the depreciation of the shadow exchange rate.

\section{Solution for the optimum}

Define $\mu_{t}$ as the ratio of real balances to output

$$
\mu_{t} \equiv \frac{M_{t-1}}{P_{t} Y_{t}},
$$

$\Delta \rho_{t}$ as the ratio of net reserve inflows to GDP

$$
\Delta \rho_{t} \equiv \frac{S_{t} R_{t}-\left(1+i_{t}^{*}\right) S_{t} R_{t-1}}{P_{t} Y_{t}},
$$

and $b_{t}$ as the outstanding public debt to GDP ratio

$$
b_{t} \equiv \frac{B_{t}}{P_{t} Y_{t}} .
$$

Inter-temporal optimization by the central bank then leads to the Euler condition,

$$
q_{t}=\beta E_{t}\left[\left(1+i_{t}^{*}+\gamma_{t}\right) q_{t+1}\right],
$$

where $q_{t}$ is the costate variable associated with the public sector budget constraint. The necessary conditions include

$$
q_{t}=\frac{\theta\left(s_{t}-s_{t-1}\right)+\alpha\left(y_{t}-y^{*}\right)}{\Omega \mu_{t}}
$$

and the transversality condition

$$
\lim _{t \rightarrow \infty} \beta^{t} q_{t} b_{t}=0 .
$$

To derive a relationship between capital inflows and the exchange rate, we linearize about the deterministic steady state. This is given by

$$
\bar{q}=0,
$$




$$
\begin{gathered}
\bar{w}_{t}=s_{t-1}+\frac{\alpha}{\theta} y^{*}, \\
\overline{\Delta s_{t}}=\left(\bar{s}_{t}-\bar{s}_{t-1}\right)=\frac{\alpha}{\theta} y^{*}
\end{gathered}
$$

and

$$
\bar{b}=\left(1+\overline{i^{*}}+\bar{\gamma}\right) \bar{b}+\bar{g}+\overline{\Delta \rho}-\bar{\mu}\left(\bar{s}_{t}-\bar{s}_{t-1}\right),
$$

where $g_{t}$ is the primary deficit to GDP ratio $(\bar{g}$ is the ratio in the deterministic steady state).

Linearization of the dynamics about the steady state gives

$$
\left.d q_{t}=\beta E_{t}\left[\left(1+\overline{i^{*}}+\bar{\gamma}\right) d q_{t+1}+d\left(i_{t+1}^{*}+\gamma_{t+1}\right) d q_{t+1}\right)\right]
$$

where the differential operator is used to denote deviations from deterministic steady-state values $\left(d x_{t} \equiv x_{t}-\bar{x}\right)$. This becomes upon substitution

$$
\Delta s_{t}=\beta\left(1+\overline{i^{*}}+\bar{\gamma}\right) E_{t}\left[\Delta s_{t+1}\right]+\beta \sigma_{s i}
$$

treating the correlation between the rate of nominal depreciation and the foreign rate of interest inclusive of premium,

$$
\sigma_{s i}=E_{t}\left[\Delta s_{t+1} d\left(i_{t+1}^{*}+\gamma_{t+1}\right)\right]
$$

as a constant evaluated in the stochastic stationary state. Note that at the steady state

$$
d \Delta s_{t}=\Delta s_{t}
$$

and

$$
d q_{t}=\left(\frac{\alpha^{2}+\theta}{\Omega \bar{\mu}}\right) d \Delta s_{t} .
$$

The exchange rate equation evaluated about the steady state gives

$$
\Delta s_{t}=\Omega^{-1}\left\{\Delta m_{t}+\delta \Delta i_{t}^{*}-\left(\Delta \nu_{t}+\varphi \Delta u_{t}\right)+\delta E_{t}\left[\Delta s_{t+1}\right]\right\}
$$


and the budget identity becomes

$$
d b_{t}=\left(1+\overline{i^{*}}+\bar{\gamma}\right) d b_{t-1}+\bar{b} d\left(1+i_{t}^{*}+\gamma_{t}\right)+d g_{t}+d \Delta \rho_{t}-\bar{\mu} \Delta m_{t}
$$

Substitution using the linearized Euler condition and exchange rate equation leads to the two equation system:

$$
E_{t}\left[\Delta s_{t+1}\right]=\beta^{-1}\left(1+\overline{i^{*}}+\bar{\gamma}\right)^{-1} \Delta s_{t}-\left(1+\overline{i^{*}}+\bar{\gamma}\right)^{-1} \sigma_{s i}
$$

and

$$
\begin{aligned}
d b_{t}= & \left(1+\overline{i^{*}}+\bar{\gamma}\right) d b_{t-1}-\bar{\mu}\left[\Omega-\delta \beta^{-1}\left(1+\overline{i^{*}}+\bar{\gamma}\right)^{-1}\right] \Delta s_{t} \\
& +d g_{t}+d \Delta \rho_{t}+\bar{\mu}\left[\delta \Delta i_{t}^{*}-\left(\Delta \nu_{t}+\varphi \Delta u_{t}\right)\right]+\bar{b} d\left(i_{t}^{*}+\gamma_{t}\right) .
\end{aligned}
$$

We let $i_{t}^{*}, \gamma_{t}, u_{t}$ and $\Delta \nu_{t}$ all be iid ${ }^{4}$. The saddle-path stable solution satisfying the transversality condition is given by

$$
\Delta s_{t}=\psi d b_{t-1}+E_{t} \sum_{s=t}^{\infty}\left(1+\overline{i^{*}}+\bar{\gamma}\right)^{-(s-t)}\left(\psi\left(d g_{s}+d \Delta \rho_{s}+\varepsilon_{s}\right)+\frac{\sigma_{s i}}{\left(1+\bar{i}^{*}+\bar{\gamma}\right)}\right)
$$

where

$$
\psi \equiv\left[\frac{\beta\left(1+\overline{i^{*}}+\bar{\gamma}\right)^{2}-1}{\bar{\mu}\left(\beta \Omega\left(1+\overline{i^{*}}+\bar{\gamma}\right)-\delta\right)}\right]
$$

and

$$
\varepsilon_{t} \equiv \bar{\mu}\left[\delta \Delta i_{t}^{*}-\left(\Delta \nu_{t}+\varphi \Delta u_{t}\right)\right]+\bar{b} d\left(i_{t}^{*}+\gamma_{t}\right)
$$

See the appendix for the details of this solution.

\footnotetext{
${ }^{4}$ As we mentioned above, the shocks to money demand $\nu_{t}$ could exhibit first-order serial correlation.
} 
This implies that the change in the rate of nominal depreciation for a shock at time $t$ is given by

$$
d \Delta s_{t}=\psi\left(d b_{t-1}+d g_{t}+d \Delta \rho_{t}+\varepsilon_{t}\right)+\psi E_{t} \sum_{s=t+1}^{\infty}\left(1+\overline{i^{*}}+\bar{\gamma}\right)^{-(s-t)}\left(d g_{s}+d \Delta \rho_{s}+\varepsilon_{s}\right) .
$$

If we assume that shocks are i.i.d., equation 3.14 satisfies

$$
d \Delta s_{t}=\psi\left(d b_{t-1}+d g_{t}+d \Delta \rho_{t}+\varepsilon_{t}\right)
$$

Alternatively, we allow the primary budget deficit, reserve inflows, and either the first-difference in the world rate of interest or shocks to money demand to follow a first-order autoregressive process. In particular, let $d g_{t}, \Delta \rho_{t}$, and $\varepsilon_{t}$ satisfy

$$
\begin{gathered}
d g_{t}=\eta_{1} d g_{t-1}+\zeta_{1 t} \\
\Delta \rho_{t}=\eta_{2} \Delta \rho_{t-1}+\zeta_{2 t},
\end{gathered}
$$

and

$$
\varepsilon_{t}=\eta_{3} \varepsilon_{t-1}+\zeta_{3 t}
$$

where $0 \leq \eta_{j}<1$ and $E_{t-1}\left(\zeta_{j t}\right)=0(j=1,2,3)$.

For these stationary processes, we have that

$d \Delta s_{t}=\psi\left(d b_{t-1}+\left(\frac{1+\overline{i^{*}}+\bar{\gamma}}{1+\overline{i^{*}}+\bar{\gamma}-\eta_{1}}\right) d g_{t}+\left(\frac{1+\overline{i^{*}}+\bar{\gamma}}{1+\overline{i^{*}}+\bar{\gamma}-\eta_{2}}\right) d \Delta \rho_{t}+\left(\frac{1+\overline{i^{*}}+\bar{\gamma}}{1+\overline{i^{*}}+\bar{\gamma}-\eta_{3}}\right) \varepsilon_{t}\right)$ 


\section{Empirical Results}

\subsection{Single Equation Specification}

In this section, we estimate our saddle-path stable solution for i.i.d. and firstorder autoregressive shocks for a panel of dirty-floating nations. Our theory is likely to omit a number of important country and time-specific characteristics which also affect the path of exchange rates. We therefore introduce $\xi_{i}$ to account for country-specific fixed effects which are time-invariant and $\phi_{t}$ to account for time-specific fixed effects.

By equations 3.15 and ??, the change in the rate of nominal exchange rate depreciation of country $i$ in period $t$ satisfies

$$
\begin{aligned}
d \Delta s_{t}= & \xi_{i}+\phi_{t}+\psi d b_{t-1}+\left(\psi \Psi_{1}\right) d g_{t}+\left(\psi \Psi_{2}\right) d \Delta \rho_{t} \\
& +\left(\psi \Psi_{3} \bar{\mu} \delta\right) \Delta i_{t}^{*}+\left(\psi \Psi_{3} \bar{b}\right) d\left(i_{t}^{*}+\gamma_{t}\right)+e_{t}
\end{aligned}
$$

where $e_{t}$ is the disturbance term

$$
e_{t}=-\left(\psi \Psi_{3} \bar{\mu}\right)\left(\Delta v_{i t}+\varphi \Delta u_{i t}\right)
$$

and

$$
\Psi_{j}=\left(\frac{1+\overline{i^{*}}+\bar{\gamma}}{1+\overline{i^{*}}+\bar{\gamma}-\eta_{j}}\right) \geq 0 ; \quad(j=1,2,3)
$$

The above specification nests the specifications under the alternative assumptions that the shocks are first-order autocorrelated and that they are i.i.d. Under both specifications, all four coefficient values are predicted to be positive. With the additional assumption that the shocks are i.i.d. we have the additional parameter restriction

$$
\Psi_{1}=\Psi_{2}=\Psi_{3}=1
$$


We first sweep the data of its period means so that we can do away with the time-specific effects, $\phi_{t}$. Next, we eliminate the country-specific fixed effects by differencing the data. We obtain

$$
\begin{aligned}
\left(\Delta s_{i, t}-\Delta s_{i, t-1}\right)= & \psi\left(b_{i, t-1}-b_{i, t-2}\right)+\left(\psi \Psi_{1}\right)\left(g_{i, t}-g_{i, t-1}\right) \\
& +\left(\psi \Psi_{2}\right)\left(\Delta \rho_{i t}-\Delta \rho_{i t-1}\right) \\
& +\left(\psi \Psi_{3} \bar{b}\right)\left(\gamma_{i t}-\gamma_{i t-1}\right)+\left(e_{t}-e_{t-1}\right)
\end{aligned}
$$

Our specification therefore predicts positive coefficients on the first differences of the four regressors on the right-hand side. Under the assumption the shocks are i.i.d., the model predicts an additional testable parameter restriction, namely that the coefficients on the first three regressors are equal in magnitude. We use this restriction to test the hypothesis of i.i.d. shocks below against the alternative of shocks which follow a first-order autoregressive process.

The methodology to be used in estimating equation 4.2 depends on the assumptions we are willing to make concerning the exogeneity of the right-hand side variables. We first report the ordinary least squares (OLS) results for the specification above. However, these estimates will be inconsistent if the right-hand side variables are endogenous. This would appear to be a particular problem for the net capital inflows term, as capital inflows may respond to exchange rate movements as a signal of future monetary policy.

We respond to the potential endogeneity problem in two ways. First, we allow all of the right-hand-side variables to be endogenous and then instrument for them with lagged dependent variables. This specification will be consistent under the assumption that the right-hand-side variables are weakly exogenous, i.e. that $E\left(\Delta X_{i t} \Delta \epsilon_{i s}\right)=0$ for all right-hand-side variables $X_{i t}$ for all $s>t$. We 
then estimate the specification in an OLS instrumental variables (IV) framework and a Generalized Method of Moments (GMM) framework. Second, we allow for endogeneity only in the capital inflows term and provide an explicit specification which we can estimate using a simultaneous equations framework in the following section.

\subsection{Data}

We use a balanced panel of quarterly data for 24 countries from February 1984 through April 1992. The time series was chosen to correspond to a period where countries in the sample were receiving high levels of capital inflows. Data sources are listed in detail in the data appendix. The summary statistics for these countries are listed in Table 1.

An issue which immediately arises in Table 1 is that we are pooling across countries which report themselves as pursuing different exchange rate regimes. Our panel includes 7 countries which claim to have pursued a pegged regime throughout the period and 10 which pursue a managed float throughout the period. ${ }^{5}$ The eight remaining countries in the sample changed their designation between pegged and floating at some point during the sample period.

Among these various country groups, the greatest concern with pooling would arise with those which maintained a pegged regime throughout the period. Because they were attempting to maintain a peg, these countries may have been systematically more reluctant to adjust their spot rate in the face of shocks than

\footnotetext{
${ }^{5}$ Two of the countries switched their exchange rate regime designations during the sample period from managed float to float. Costa Rica switched in the first quarter of 1992 while the Philippines switched in the third quarter of 1984.
} 
countries in a managed floating regime. However, all of these countries adjusted their pegs over the sample period, some numerous times.

There is some reason to suspect that these countries do behave differently as a group than their counterparts in the other groups. The average level of the absolute value of log differences in spot exchange rates, the dependent variable in our specification, for the 24 countries in the sample is 0.0518 . In contrast, the countries which maintained a peg throughout the sample period had an average of 0.0198 . However the countries which pursued a managed float throughout the period were not that different, with an average log difference in the spot rate of 0.0266. It turns out that the greatest volatility was experienced in those countries which either abandoned a peg in favor of a floating regime, or vice versa. For these countries, the average log difference in spot rate was 0.1158. However, to maintain a balanced panel, we classify those countries which switched between regimes as in our "managed floating" group. ${ }^{6}$

Finally, $\gamma_{i t}$ is unobservable directly because it is a function of the expected future spot rate, as shown above in equation 2.5. Estimation of equation 4.2 then requires some estimate of the expected future spot rate to allow us to construct an estimate of $\gamma_{i t}$. A number of different proxies have been used in the literature. ${ }^{7}$ We proceed under the assumption that agents have perfect foresight in predicting

\footnotetext{
${ }^{6}$ To account for potential differences between these groups, we examined the robustness of our results below to the exclusion of those countries which maintained a pegged regime for the duration of the sample. Our results with these countries excluded were very similar to those for the entire sample. The simultaneous equation results are reported in Table 4, while all of the single equation results are available from the authors upon request.

${ }^{7}$ For example, Goldberg [1994] estimates a series of rolling regressions, while Frankel and Okongwu [1996] use survey data.
} 
exchange rate changes. While this assumption is somewhat strong in levels, we note that after differencing the panel data, which we do below to eliminate country-specific fixed effects, the specification run is exactly equivalent to that which would emerge under the opposite extreme assumption that agents expected the exchange rate to follow a random walk. Our specification therefore nests both the perfect foresight and the random walk specifications used in Kletzer and Spiegel [1998].

\subsection{Single Equation Results}

The results for the full-sample regression are shown in Table 2. The primary result is the strong performance of the term representing the quasi-fiscal costs of sterilization, $\left(\gamma_{i t}-\gamma_{i t-1}\right)$. This term enters significant and positive for all specifications with or without the parameter restriction implied by the assumption that the shocks are i.i.d., i.e. the restriction that the coefficients on the first three regressors are equal. The performance of the other three coefficients, however, reflect varying degrees of sensitivity to our treatments for endogeneity and the application of the i.i.d. coefficient value restriction.

With the first three parameters constrained to be equal, all three of these variables enter significantly positive, as predicted, in both the OLS and IV specifications. However, they are insignificant in the GMM specification. With the coefficient values of the first three regressors unrestricted, their performance varies. In the OLS specification, $\left(g_{i, t}-g_{i, t-1}\right)$ and $\left(\Delta \rho_{i, t}-\Delta \rho_{i, t-1}\right)$ enter significantly with their predicted positive signs, but $\left(b_{i, t-1}-b_{i, t-2}\right)$ enters significantly with the incorrect negative sign. After instrumenting, these three variables are insignificant in both the IV and GMM specifications. 
We also report the results of a formal F-test concerning the parameter restriction implied by the assumption that the shocks in the model are i.i.d. For the OLS regression, we obtain an F-statistic of 13.678 for the test of the restricted versus unrestricted specification. This would imply a rejection of the assumption that shocks are i.i.d. in our model in favor of our more general autoregressive specification. However, in the IV and GMM specification, we obtained a higher sum-of-squared errors in terms of fitting the original regressors (rather than those fitted with our instruments) with the unrestricted specification than with the first three coefficients restricted. Since endogeneity is a serious issue in this specification, this provides some evidence in support of the restrictions imposed by the assumption that the shocks are i.i.d.

The diagnostic results for the validity of the GMM specification are also presented. We find no presence of second-order serial correlation in any specification, indicating that the Sargen statistic is a valid test of the over-identifying restrictions in the model. Our results from the Sargen statistic strongly fail to reject the null hypothesis that the over-identifying restrictions in our specification are valid.

\subsection{Simultaneous Equation Specification}

In this section, we examine an explicit simultaneous equation system with two endogenous variables: $\Delta \rho_{i, t}$ and $\Delta s_{i, t}$. We specify an equation for the determination of net capital inflows using variables which are perceived as correlated with the desirability of a nation's assets. In addition to exchange rate movements, $\Delta s_{i, t}$, which might affect investor expectations concerning the path of future monetary policy, we also specify net capital inflows as dependent upon the domestic debt-to- 
export ratio, $D E B T_{i t}$, an index of domestic terms of trade, $T O T_{i t}$, as well as the current period's income shock $\widetilde{y}_{i t}{ }^{8}$ In differences with the time dummies swept, our second equation then becomes

$$
\begin{aligned}
\left(\Delta \rho_{i, t}-\Delta \rho_{i, t-1}\right)= & \alpha_{1}\left(\Delta s_{i, t}-\Delta s_{i, t-1}\right) \\
& +\alpha_{2}\left(D E B T_{i, t}-D E B T_{i, t-1}\right) \\
& +\alpha_{3}\left(T O T_{i, t}-T O T_{i, t-1}\right) \\
& +\alpha_{4}\left(\widetilde{y}_{i, t}-\widetilde{y}_{i, t-1}\right)+u_{i t} .
\end{aligned}
$$

The results for the simultaneous equation specification with coefficient values unrestricted are reported in Table $3 .{ }^{9}$ The quasi-fiscal cost variable in the first equation, $\left(\gamma_{i t}-\gamma_{i t-1}\right)$, enters significantly with its predicted positive sign. The government deficit variable, $\left(g_{i t}-g_{i t-1}\right)$, is also positive and significant. However, the stock of debt, $\left(b_{i t-1}-b_{i t-2}\right)$, enters significantly with the incorrect negative sign. The net capital inflows variable, $\left(\Delta \rho_{i t}-\Delta \rho_{i t-1}\right)$, is insignificant.

We also report the results of estimation with a sub-sample which excludes the nations which claimed to maintain exchange rate pegs throughout the estimation period. Our sub-sample yields similar results. The quasi-fiscal cost variable in the first equation, $\left(\gamma_{i t}-\gamma_{i t-1}\right)$, again enters significantly with its predicted positive sign. The government deficit variable, $\left(g_{i t}-g_{i t-1}\right)$, is also still positive and significant. However, the stock of debt variable, $\left(b_{i t-1}-b_{i t-2}\right)$, now fails to enter

\footnotetext{
${ }^{8}$ The method of calculating $\widetilde{y}_{i t}$ is described in the data appendix.

${ }^{9} \mathrm{We}$ also ran the simultaneous equation specification with the first three coefficients constrained, as predicted by the theory. However, as in the single equation specifications, F-tests rejected this restriction. The restricted specification results are similar to those in the singleequation specification and are available upon request.
} 
significantly. The net capital inflows variable, $\left(\Delta \rho_{i t}-\Delta \rho_{i t-1}\right)$, is insignificant as before, but now enters with its predicted positive point estimate.

For completeness, we also report the results of the second regression, the determinants of the magnitude of capital inflows. As expected, the difference in the rate of exchange rate depreciation, $\left(\Delta s_{i t}-\Delta s_{i t-1}\right)$, is a very significant predictor of the level of capital inflows, suggesting that net capital inflows are indeed endogenous. Income shocks, $\left(\widetilde{y}_{i t}-\widetilde{y}_{i t-1}\right)$, are also significantly positive, as would be expected. The stock of debt is significantly negative, as would be expected. Finally, the terms of trade variable fails to enter significantly. The results with the omission of the pegged countries from the sample are similar, with the exception that the change in the stock of debt fails to enter significantly.

\section{Conclusion}

Our theoretical results demonstrate that a forward-looking central bank will incorporate sterilization costs in its monetary policy decisions, choosing more accommodating nominal exchange rate strategies the higher is the cost of maintaining an announced peg or crawl. Our empirical results support this claim. Using a specification which directly follows the linearized decision rule from the theory, we confirm that the central banks in our panel of 24 developing countries during a period of high capital inflows did respond to sterilization costs in their nominal exchange rate policy.

The importance of these costs in central bank decisions, however, still comes down to the level of true deviations from interest rate parity. As we suggested in the introduction, our estimates of deviations from interest rate parity in these 
countries must represent upper bounds, as some portion of the spread paid on domestic securities over foreign assets must represent true differences in default risk. To the extent that spreads represent true default risk premia, rather than deviations from interest rate parity, actual sterilization costs are reduced.

However, it is clear that developing country governments do behave as if sterilization is a costly process. Most countries only attempt sterilization over limited periods, eventually choosing to either accommodate the capital inflow through an expansion of the domestic money supply or through an appreciation of the nominal exchange rate. The limited duration of sterilization programs suggest that the costs considered in this paper are incorporated into central bank decisions. 


\section{Appendix}

The eigenvalues of the solution for the optimum are

$$
\lambda_{1}=\left(1+\overline{i^{*}}+\bar{\gamma}\right)
$$

and

$$
\lambda_{2}=\beta^{-1}\left(1+\overline{i^{*}}+\bar{\gamma}\right)^{-1},
$$

and the eigenvectors are

$$
v_{1}=\left[\begin{array}{l}
E \Delta s \\
d b
\end{array}\right]=\left[\begin{array}{l}
0 \\
1
\end{array}\right]
$$

and

$$
v_{2}=\left[\begin{array}{l}
E \Delta s \\
d b
\end{array}\right]=\left[\begin{array}{l}
\psi \\
1
\end{array}\right]=\left[\begin{array}{l}
\frac{\beta^{-1}\left(1+\overline{i^{*}}+\bar{\gamma}\right)^{-1}-\left(1+\overline{i^{*}}+\bar{\gamma}\right)}{\bar{\mu}\left[-(1+\delta+\alpha \varphi)+\delta \beta^{-1}\left(1+\bar{i}^{*}+\bar{\gamma}\right)^{-1}\right]} \\
1
\end{array}\right]
$$

The saddle-path stable solution which satisfies the transversality condition is then given by

$$
\begin{aligned}
& {\left[\begin{array}{ll}
E_{t} \Delta s_{t+1} \\
d b_{t}
\end{array}\right]=\left[\begin{array}{ll}
\beta^{-1}\left(1+\overline{i^{*}}+\bar{\gamma}\right)^{-1} & 0 \\
-\bar{\mu}\left[(1+\delta+\alpha \varphi)-\delta \beta^{-1}\left(1+\overline{i^{*}}+\bar{\gamma}\right)^{-1}\right] & \left(1+\overline{i^{*}}+\bar{\gamma}\right)
\end{array}\right]\left[\begin{array}{l}
\Delta s_{t} \\
d b_{t-1}
\end{array}\right]} \\
& +\left[\begin{array}{l}
-\left(1+\overline{i^{*}}+\bar{\gamma}\right)^{-1} \sigma_{s i} \\
d g_{t}+d\left[\Delta \rho_{t}\right]+\bar{\mu}\left[\delta \Delta i_{t}^{*}-\left(\Delta \nu_{t}+\varphi \Delta u_{t}\right)\right]+\bar{b} d\left(1+i_{t}^{*}+\gamma_{t}\right)
\end{array}\right]
\end{aligned}
$$




\section{Data Appendix}

Data is quarterly from the second quarter of 1984 through the fourth quarter of 1992. For all countries other than Taiwan, the following data was obtained from the International Monetary Fund's International Financial Statistics: exchange rate, line ae; nominal GDP, line 99b; real GDP, line 99bp; government deficit, line 80 (except as noted below); exports, line 70d; government bonds, line 32an; foreign reserves, line11; three month interest rates, line 60c where available (exceptions are noted below); CPI, line 64. Interpolated annual nominal GDP data (line 99b) was used except for: Mexico, Israel, Korea, Philippines and Taiwan, which had quarterly data available. Data for these variables for Taiwan was obtained from Financial Statistics, Taiwan District. The terms of trade index is annual data obtained from the Penn World Tables. Annual foreign debt data is from the World Bank STARS database, except Israel, which is from Government Finance Statistics. Annual data was interpolated into quarterly frequencies.

Countries for which line 60c were not available include Argentina (60b), Bolivia (60p), Chile (60p), Costa Rica (60), Honduras (61), Venezuela (61), India (60b), Korea (60b), Pakistan (60b), Mauritius (60b). Some missing observations were interpolated. Details are available from the authors. Interest rate data for Taiwan was 31-90 day commercial paper rate from Financial Statistics, Taiwan District. Interest rate data for Indonesia was obtained from Bank of Indonesia. Data for Malaysia and Thailand were 3 month T-bill and lending rate average respectively, obtained from DRI.

Annual government deficit data was interpolated into quarterly data over some range for Bolivia, Chile, Honduras, Israel, Sri Lanka, India, Pakistan, Mauritius, Zimbabwe, Fiji, Papua New Guinea, Taiwan, and Indonesia. Further details are available from the authors. 
Table 1

\section{Summary of Exchange Rate Regimes in the Sample ${ }^{10}$}

\begin{tabular}{|c|c|c|c|c|c|c|c|}
\hline Country & $\underline{\text { Regime }}^{11}$ & $\underline{\bar{s}}$ & $\underline{\operatorname{Max} \mathrm{s}}$ & $\underline{\operatorname{Min} \mathrm{s}}$ & $|\overline{\Delta s}|$ & $\underline{\operatorname{Max} \Delta s}$ & $\underline{\operatorname{Min} \Delta s}$ \\
\hline Argentina & $m f-f-p$ & 0.29 & 1.00 & $5^{*} 10^{-6}$ & 0.36 & 2.80 & $-7^{*} 10^{-3}$ \\
\hline Barbados & $\mathrm{p}$ & 2.00 & 2.01 & 2.00 & $2^{*} 10^{-4}$ & 0.00 & $-6^{*} 10^{-3}$ \\
\hline Bolivia & $p-f$ & 2.36 & 4.10 & $2^{*} 10^{-3}$ & 0.26 & 2.72 & $3^{*} 10^{-3}$ \\
\hline Chile & $\mathrm{mf}$ & 248.75 & 382.33 & 77.06 & 0.05 & 0.55 & -0.07 \\
\hline Costa Rica & mf-f & 82.36 & 137.43 & 44.00 & 0.03 & 0.11 & -0.02 \\
\hline Fiji & $\mathrm{p}$ & 1.35 & 1.56 & 1.07 & 0.01 & 0.18 & -0.05 \\
\hline Honduras & p-mf-f & 2.78 & 5.83 & 2.00 & 0.03 & 0.97 & 0.00 \\
\hline India & $\mathrm{mf}$ & 16.47 & 26.20 & 11.19 & 0.03 & 0.20 & -0.04 \\
\hline Indonesia & $\mathrm{mf}$ & 1630 & 2062 & 1014 & 0.03 & 0.37 & 0.00 \\
\hline Israel & $\mathrm{mf}-\mathrm{p}$ & 1.73 & 2.76 & 0.24 & 0.09 & 0.53 & -0.05 \\
\hline Kenya & $\mathrm{p}$ & 21.005 & 36.22 & 14.48 & 0.03 & 0.10 & -0.03 \\
\hline Korea & $\mathrm{mf}$ & 777.72 & 891.70 & 667.20 & $1^{*} 10^{-4}$ & 0.03 & -0.06 \\
\hline Malawi & $\mathrm{p}$ & 2.49 & 4.40 & 1.39 & 0.03 & 0.22 & -0.10 \\
\hline Malaysia & $\mathrm{p}-\mathrm{mf}$ & 2.60 & 2.78 & 2.32 & $4^{*} 10^{-3}$ & 0.06 & -0.05 \\
\hline Mauritius & $\mathrm{p}$ & 14.61 & 17.00 & 12.18 & $9 * 10^{-3}$ & 0.13 & -0.10 \\
\hline Mexico & $\mathrm{mf}$ & 1.88 & 3.12 & 0.17 & 0.09 & 0.34 & $-2^{*} 10^{-3}$ \\
\hline Pakistan & $\mathrm{mf}$ & 19.56 & 25.70 & 13.98 & 0.02 & 0.07 & $-4^{*} 10^{-3}$ \\
\hline Papua N.G. & $\mathrm{p}$ & 0.93 & 1.02 & 0.83 & 0.01 & 0.13 & -0.06 \\
\hline Philippines & mf-f & 22.22 & 28.00 & 18.00 & 0.02 & 0.25 & -0.07 \\
\hline Sri Lanka & $\mathrm{mf}$ & 34.25 & 46.00 & 25.17 & 0.02 & 0.15 & $-2^{*} 10^{-3}$ \\
\hline Taiwan & $\mathrm{mf}$ & 31.04 & 40.40 & 24.65 & 0.01 & 0.03 & -0.10 \\
\hline Thailand & mf-p & 25.69 & 27.55 & 23.00 & $3^{*} 10^{-3}$ & 0.17 & -0.04 \\
\hline Venezuela & $p-f$ & 30.29 & 79.45 & 7.50 & 0.07 & 0.93 & 0.00 \\
\hline Zimbabwe & $\mathrm{p}$ & 2.48 & 5.48 & 1.20 & 0.05 & 0.44 & -0.05 \\
\hline
\end{tabular}

\footnotetext{
${ }^{10}$ Source: International Monetary Fund Exchange Rate Restrictions and Arrangements.

${ }^{11} \mathrm{p}=\mathrm{peg} ; \mathrm{mf}=$ managed float; $\mathrm{f}=$ float
} 
Table 2

\section{Single-Equation Specification Results ${ }^{12}$}

Dependent Variable: $d \Delta s_{i t}$ :

\begin{tabular}{|c|c|c|c|c|c|c|}
\hline & $\underline{\mathrm{OLS}}$ & $\frac{\text { OLS }}{\text { Rest. })}$ & $\underline{\text { IV }}$ & (Rest.) & $\underline{\mathrm{GMM}}$ & $\frac{\text { GMM }}{\text { (Rest.) }}$ \\
\hline $\mathrm{b}_{i t-1}-\mathrm{b}_{i t-2}$ & $\begin{array}{c}-0.2213^{* *} \\
(0.0949)\end{array}$ & 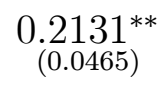 & $\begin{array}{l}0.2629 \\
(0.5111)\end{array}$ & $0.1712^{* *}$ & $\begin{array}{l}0.1203 \\
(0.5039)\end{array}$ & $\begin{array}{l}0.1474 \\
(0.2412)\end{array}$ \\
\hline $\mathrm{g}_{i t}-\mathrm{g}_{i t-1}$ & $\underset{(0.0814)}{0.4569 * *}$ & $\begin{array}{c}0.2131 * * \\
(0.0465)\end{array}$ & $\begin{array}{l}0.1195 \\
(0.2025)\end{array}$ & $0.1712^{* *}$ & $\begin{array}{l}0.1591 \\
(0.3222)\end{array}$ & $\begin{array}{l}0.1474 \\
(0.2412)\end{array}$ \\
\hline$\Delta \rho_{i t}-\Delta \rho_{i t-1}$ & $\underset{(0.0832)}{0.3667^{* *}}$ & $\begin{array}{c}0.2131 * * \\
(0.0465)\end{array}$ & $\begin{array}{l}0.1788 \\
(0.1763)\end{array}$ & $0.1712^{* *}$ & $\begin{array}{l}0.2155 \\
(0.8162)\end{array}$ & $\begin{array}{l}0.1474 \\
(0.2412)\end{array}$ \\
\hline$\gamma_{i t}-\gamma_{i t}$ & $\underset{\left(3 E^{-7}\right)}{2 E^{-6 * *}}$ & $\underset{\left(4 E^{-7}\right)}{2 E^{-6 * *}}$ & $\begin{array}{c}3 E^{-6 * *} \\
\left(5 E^{-7}\right)\end{array}$ & $\begin{array}{c}3 E^{-6 * *} \\
\left(5 E^{-7}\right)\end{array}$ & $\begin{array}{c}3 E^{-6 * *} \\
\left(9 E^{-7}\right)\end{array}$ & $\begin{array}{c}3 E^{-6 * * *} \\
\left(9 E^{-7}\right)\end{array}$ \\
\hline \# obs. & 792 & 792 & 792 & 792 & 792 & 792 \\
\hline DW & 0.0408 & 0.0401 & 0.0454 & 0.0452 & 0.0465 & 0.0458 \\
\hline F Test & & 13.6738 & & 0.0512 & & \\
\hline Sargan & & & & & 0.0104 & 0.0306 \\
\hline
\end{tabular}

\footnotetext{
${ }^{12}$ Rest. refers to restricted specification. First three reressors are restricted to have same coefficient value. Standard errors in parentheses. * indicates significance at $10 \%$ confidence level. ** indicates singificance at $5 \%$ confidence level.
} 


\section{Table 3 \\ Simultaneous Equation Model ${ }^{13}$}

Equation 1: Dependent Variable: $d \Delta s_{t}$

Full Sample Pegged Countries Omitted

$\begin{array}{ccc}b_{i t}-b_{i t-1} & \begin{array}{c}0.2223^{* *} \\ (0.0857)\end{array} & \begin{array}{c}-0.1377 \\ (0.1020)\end{array} \\ g_{i t}-g_{i t-1} & \begin{array}{c}0.4127^{* *} \\ (0.0811)\end{array} & \begin{array}{c}0.6551^{* *} \\ (0.1180)\end{array} \\ \Delta \rho_{i t}-\Delta \rho_{i t-1} & \begin{array}{c}-0.2780 \\ (0.5021)\end{array} & \begin{array}{c}0.1826 \\ (0.5590)\end{array} \\ \gamma_{i t}-\gamma_{i t-1} & \underset{\left(4 E^{-7}\right)}{2 E^{-6 * *}} & \underset{\left(4 E^{-7}\right)}{2 E^{-6 * *}} \\ \text { DW } & 0.0365 & 0.0441 \\ \text { \# obs } & 792 & 561\end{array}$

$\underline{\text { Equation 2: Dependent Variable: }} \Delta \rho_{t}-\Delta \rho_{t-1}$

\begin{tabular}{|c|c|c|}
\hline & Full Sample & Pegged Countries Omitted \\
\hline$\Delta s_{t}-\Delta s_{t-1}$ & $-\underset{(0.0713)}{0.201)^{* *}}$ & $-{ }^{-0.2076^{* *}}$ \\
\hline $\operatorname{debt}_{t}-$ debt $_{t-1}$ & $-\underset{(0.0051)}{0.0143^{* *}}$ & $\begin{array}{l}-0.0095 \\
(0.0078)\end{array}$ \\
\hline $\mathrm{TOT}_{t}-\mathrm{TOT}_{t-1}$ & $\begin{array}{l}4 E^{-5} \\
\left(2 E^{-4}\right)\end{array}$ & $\begin{array}{l}-3 E^{-5} \\
\left(2 E^{-4}\right)\end{array}$ \\
\hline$\widetilde{y}_{t}-\widetilde{y}_{t-1}$ & $\begin{array}{l}0.0820^{* *} \\
(0.0267)\end{array}$ & $\underset{(0.0290)}{0.1108^{* *}}$ \\
\hline
\end{tabular}

\footnotetext{
${ }^{13}$ Unrestricted specification. Standard errors in parentheses. * indicates significance at $10 \%$ confidence level. $* *$ indicates singificance at $5 \%$ confidence level.
} 


\section{References}

[1] Burnside, Craig, Martin Eichenbaum and Sergio Rebelo. (1998), "Prospective deficits and the Asian currency crisis," NBER Working Paper no. 6758, October.

[2] Buiter, Willem H. (1987), "Borrowing to defend the exchange rate and the timing and magnitude of speculative attacks," Journal of International Economics, 23, 221-239.

[3] Calvo, Guillermo A. (1991), "The Perils of Sterilization," International Monetary Fund Staff Papers, 38 (4),

921-926.

[4] Calvo, Guillermo A., Leonardo Leiderman and Carmen Reinhart (1993), "Capital Inflows and Real Exchange Rate Appreciation in Latin America: The Role of External Factors," International Monetary Fund Staff Papers, 40 (1), $108-151$.

[5] Calvo, Guillermo A., Leonardo Leiderman and Carmen Reinhart (1996), "Inflows of Capital to Developing Countries in the 1990s," Journal of Economic Perspectives, 10 (2), 123-139.

[6] Craine, Roger. (1999), "Exchange Rate Credibility, the Agency Cost of Capital and Devaluation," mimeo, January.

[7] Daniels, Joseph (1997), "Optimal Sterilization in Interdependent Economies," Journal of Economics and Business, 49, 43-60.

[8] Flood, Robert P. and Peter M. Garber (1984a), "Gold Monetization and Gold Discipline," Journal of Political Economy, 92, 90-107.

[9] Flood Robert P. and Peter M. Garber (1984b), "Collapsing Exchange Rate Regimes: Some Linear Examples," Journal of International Economics, 17, $1-17$.

[10] Frankel, Jeffrey A. and Chudozie Okongwu (1996), "Liberalized portfolio capital inflows in emerging markets: Sterilization, expectations, and the incompleteness of interest rate convergence," International Journal of Finance and Economics, 1, 1-24. 
[11] Goldberg, Linda (1994), "Predicting exchange rate crises: Mexico revisited," Journal of International Economics, 36, 413-430.

[12] Khan, Mohsin S. and Carmen M. Reinhart (1994), "Macroeconomic management in maturing economies: The response to capital inflows," International Monetary Fund Issues Paper, March, Washington DC.

[13] Kletzer, Kenneth and Mark M. Spiegel (1998), "Speculative capital inflows and exchange rate targeting," in R. Glick ed., Managing capital flows and exchange rates, (Cambridge University Press: New York), 409-435.

[14] Krugman, Paul (1979), "A Model of Balance of Payments Crises," Journal of Money, Credit and Banking, 11, 311-325.

[15] Natividad, Fidelina and Joe A. Stone (1990), "A general equilibrium model of exchange rate intervention with variable sterilization," Journal of International Economics, 29, 133-145.

[16] Obstfeld, Maurice (1986), "Rational and self-fulfilling balance of payments crises," American Economic Review, 76, 72-81.

[17] Obstfeld, Maurice (1995), "The Logic of Currency Crises," in Eichengreen B., J. Frieden, and J. von-Hagen eds., Monetary and Fiscal Policy in an Integrated Europe, (Springer: New York).

[18] Reinhart, Carmen M. and R. Todd Smith (1998), "The macroeconomic effects of taxing capital inflows," in R. Glick ed., Managing capital flows and exchange rates, (Cambridge University Press: New York), 436-464.

[19] Roubini, Nouriel (1988), "Offset and sterilization under fixed exchange rates with an optimizing central bank," NBER Working paper no. 2777, November.

[20] Spiegel, Mark M. (1995), "Sterilization of capital inflows through the banking sector: Evidence from Asia," Federal Reserve Bank of San Francisco Economic Review, 3, 14-34. 